\title{
An investigation into the factors that influence the perceived experiences and outcomes for students training in Transactional Analysis Psychotherapy in the UK and USA
}

\author{
(C) 2015 Cathy McQuaid
}

\begin{abstract}
Interpretative Phenomenological Analysis (IPA) (Smith, 1995) was applied to data from 21 out of 50 participants who had shared their training experiences during semi-structured interviews. Subjects were chosen from trainees and trainers in the USA and UK, to include 'generations' from those trained by transactional analysis originator Dr Eric Berne through to recently qualified transactional analysis psychotherapists, and including some who had ceased training before qualifying.

Results suggest that TA psychotherapy training is experienced by some as a transformational, life enhancing and reparative experience that culminates in a satisfying and rewarding career, whilst for others it is perceived as an abusive, punitive and punishing experience, bringing disillusionment, disappointment and dissatisfaction. The main contributing factors were the students' personal belief systems, motivations for undertaking the training, and relationships with the trainer, peers and the profession as a whole.

Analysis of the themes suggested that subsequent anxieties raised by participants concerned lack of information, inconsistencies in training offered by different establishments, reasons for trainees entering training and trainers' reasons for accepting them, and the significant time and resource requirements of the training. The paper includes recommendations aimed at making the training experience one that upholds the basic philosophical principles and values of TA, and promotes, develops and enhances TA psychotherapy training.
\end{abstract}

\section{Key Words}

transactional analysis training, trainers, supervisors, trainees, CTA, training needs, training concerns, psychotherapy training, non-completion rates.

\section{Literature Review}

Teaching methods and learning styles continue to play a significant part in the learning experience and these have been developed and discussed by authors who consider the advantages and disadvantages of the different theories of teaching and learning: (Zhang, 2009; Tileston, 2000; Reece \& Walker, 2007; Hillier, 2005; Minton, 2005). Research into the efficacy of learning styles instruments and theories (Coffield et al., 2004) prove inconclusive.

Training in the mental health professions, e.g. counselling, psychotherapy, psychology and psychiatry, is varied and diverse. According to Boswell et al. (2007), the core ingredients of psychotherapy training are "(a) exposure to classical works in psychotherapy and behaviour change (e.g., Bandura, Freud, and Rogers [unreferenced in original] (b) exposure to both applied (i.e., process and outcome) and basic (e.g., social, developmental, cognitive psychology) research, (c) experiential forms of training such as self-exposure to feared objects or situations (Freeston, Cromarty, \& Thwaites, 2006), rather than a purely didactic focus, (d) the systematic encouragement of self-reflection (Bennett-Levy, 2006), and (e) an emphasis on multicultural competence throughout (including both awareness and practice)."(p.380). This suggests that a broad range of theory, research, experiential work and ability for self-reflection are the core 
ingredients for psychotherapy training. How these ingredients are perceived within the philosophy of the specific psychotherapeutic approach would be likely to influence how they are incorporated into the training.

The philosophy of humanistic models of psychotherapy suggests a therapeutic goal of self actualization, (Maslow, 1987), or the Rogerian view of a returning to the 'organismic self', (Rogers, 1961). They suggest that given a safe psychological environment, people would naturally move towards greater awareness and a better fulfilment of their potentials.

Furthermore, Berne (1968) describes physis as "A force of nature which eternally strives to make things grow and to make growing things more perfect." ( $p$. 80 ). All of these philosophical principles suggest the need for growth and change. Berne seems to take it one step further by suggesting some sense of attaining or striving for 'perfection'. This has a different motivation than psychoanalytic or cognitive behaviour therapy approaches, for example, and, consequently, this would suggest that the nature of the training may also imply, either covertly or overtly, a need for growth and change within the training of therapists. This has ethical implications for the training, in that personal change may not be an aim or aspiration of the trainee when undertaking the training.

Additionally, it would seem that within the psychoanalytic, and, perhaps to a lesser extent, the humanistic traditions, personal therapy is essential to the training of a psychotherapist, (Atkinson 2006, Leader 2006, Watts 2006), but the monitoring of that personal therapy is generally left unchecked. The potential for harm here is significant, as so much of the trainee's training, both in terms of their therapy and the more academic learning, needs to take place in a trusting environment.

The quality of the learning relationship between trainee and trainer is discussed by various authors, (Reiss, 1975; Rieken, 2003; Langs, 1992; Hearst, 1990; Klain, 1975; Russell \& Staszewski, 1988; Stauble, 1965; Blohm, 2006; Bonds-White, 2003), who focus on the nature of transference and countertransference phenomenon, and how this impacts on the experience of psychotherapy training. Some writers consider the values that are held in psychotherapy and how they influence training (Carlsson \& Schubert, 2009; Palmer \& Barnes, 2001; Bergin et al., 1996; Walsh et al, 1999), and others make comparisons between the legal status and nature of psychotherapy trainings across Europe, (Ginger, 2009; Schroder, 2004; van Deurzen, 2001; Tantam et al., 2001).
General literature considers different aspects of teaching from basic counselling skills (Nelson-Jones, 2004, 2007, 2008; Evans, 2007; Hough, 2006; Geldard \& Geldard, 2002, 2005; Tolan, 2003), and cover different theoretical viewpoints (Corey, 2008; Nelson-Jones, 2005; Stewart, 2005; Kauffman \& New, 2004; Colledge, 2002; Barrelet \& Merlo, 2006; Bondolfi \& Bizzini, 2006; Hovaguimian, 2006). There are various critiques of counselling and psychotherapy theories (Feltham, 2005; Shepherd, 2004; Spence \& Markowitz, 1997; Thorne, 1944), and still more on various aspects of life that the authors consider missed from mainstream psychotherapy education (Bartoli, 2007; Sue \& Zane, 1987; McLemore \& Court, 1977)

Some of the current literature reviews the usefulness, or otherwise, of current counselling and psychotherapy trainings (Boswell \& Castonguay, 2007; Fertuck, 2007; Gordon, 2007; Greben, 2004; Elliott \& Zucconi, 2006; Knight, 2005; Reiss, 1975; Thienemann \& Joshi, 2007). Others focus on specific models or methods for teaching psychotherapy, (Halgin, 1985; Friedlander et al., 1984; Robertson, 1984; Watters et al., 1980; Melnick \& Bradsma, 1977; Robertson, 1976; Reiss, 1975; Chance, 1965; Snow \& Rickels, 1965; Bjerre, 1964; Dellis \& Stone, 1960; Derner \& Monroe, 1960; Whitaker \& Miles, 1960; Greben 2004; Leszcz,2004; Ravitz \& Silver, 2004; Lytle, 2007; Jacobs, 2002; Jacobs, 2000).

Consoli and Jester (2005a, 2005b), critique the teaching of only one specific model within the training programme and suggest an integrated approach from the start. Castonguay (2005) suggests, however, that the pre-existing knowledge needs to be taken into consideration and that integration should be a later developmental process in the training programme. Fauth et al (2007) suggest "Traditional psychotherapy training practices do not durably improve the effectiveness of trainees because they overemphasize theory, technical adherence, and didactic learning.... [and proposes that] ...Future psychotherapy training focus on a few 'big ideas', such as therapeutic responsiveness, emphasize the development of psychotherapist meta-cognitive skills (i.e. pattern recognition and mindfulness) via experiential practice and constructive feedback; and attend more closely to the organizational/treatment context." (p. 389)

Ladany (2007) goes much further and questions the validity of psychotherapy training suggesting that the relationship and work undertaken with the trainee's supervisor and personal therapist are more significant than the basic training. Others emphasise the experiential nature of psychotherapy training as being more significant, (Trotzer, 2006; White, 2004; Robertson, 1976; Carkhuff \& Truax, 1965; Truax et 
al., 1964; Elliott et al., 2004). However, Jones (1991), who initially appeared to doubt the appropriateness of training, considers that training within specific parameters is necessary and is not antithetical to the spirit of psychotherapy. Other studies have specifically focused on the issues of power and shadow influences in psychotherapy training (Jones, 2006; Feltham, 2006; Leszcz, 2004; Proctor, 2002; Chance, 1965). There is also a growing debate on where and how counselling/psychotherapy training takes place (Rizq, 2007; Parker, 2002; Wheeler \& Miller, 2002; Horton, 2002). These authors specifically consider whether universities are the best places for this type of training to be undertaken.

Transactional Analysis Psychotherapy Training To date, there has been limited research into TA psychotherapy training. Those papers that have been published are unrelated and focus on specific areas of the training process.

Newton (2003) specifically focuses on the use of Group Imagoes (Clarke, 1996) in transactional analysis training groups. She considers six different models of adult education, exploring its roots, primary uses, nature of the contract, metaphor used to describe that model, what is discounted (Schiff \& Schiff, 1971) and what is emphasised, and the shape of the group imago. She makes links with styles and methods of learning and concludes with a suggestion that trainers need to consider their training philosophy, offering a checklist for trainers to use to consider how they take account of the strengths from each model.

Cornell (1994) particularly focuses on dual relationships, born out of his own experience. He is critical of the current view that 'all dual relationships should be banned.' Instead, he recommends that a more open approach is taken, and that pros and cons are carefully and maturely considered within a boundaried and ethical framework, and that an Adult ego state decision is made on an individual basis.

Another contribution from Cornell \& Hine (1999) focuses on an explanation and description of the parallels and differences between the psychotherapy (referred to as 'clinical') and counselling fields of TA, and the apparent inflexibility of some psychotherapy members to accept the nature of counselling in a wider context, especially in Europe. TA is one of the few approaches to distinguish between counselling and psychotherapy, as well as educational and organisation fields, and this has led to misunderstandings with colleagues who perceive the 'emotional' work as purely being the domain of psychotherapists. Cornell seeks to educate colleagues into being more accepting of the broader application of TA counselling.
Bonds-White (2003) discusses the dynamics of a training group, specifically with a visiting trainer. She illustrates with a vignette how negative transferences between the student and trainer need to be confronted in a non-defensive and normalising manner. She states that time needs to be given to students who may be feeling let down or angry with the visiting trainer for not being as available as they would like them to be. She states that this needs to be explored and made transparent so that the training group remains attached and connected, rather than split, and the negative transference is not projected onto the local tutor.

More recent research undertaken into TA psychotherapy training has been that of van Rijn et al $(2008,2011)$. The training programme at Metanoia, UK, has been redesigned to move away from a traditional mix of lecture/group discussion, exercises and triads to being one that aims to be more student-led and clinically focused. In the 2008 project, the students became researchers from the start with a research question of 'How do I become an effective practitioner?' The research process clearly had difficulties but these were overcome by open communication and dialogue concerning the underlying processes with all parties concerned. She advocates "More research is needed into what made the training successful, and the possible relevance of the emotional challenges" (p. 267). Their 2011 project aimed to "evaluate the impact of the training on students' psychological health, using the 'Autonomy Questionnaire'” (p. 16). The findings suggest that although students in the later years of training would appear to report a higher degree of psychological health it is hard to know whether to attribute this to the training or the requirement for personal therapy.

Finally, Nowak (2013) investigated a related topic, in a study published after the current research had been completed, with a focus on the effectiveness of non-therapeutic TA training on 12 participants in Austria, who had completed at least a three-year TA training but of whom only one third were aiming at a higher qualification in TA. Nowak reported that "Frustrated TA trainees who give up their training or who reject TA theory in general are included in this study but they actually represent a minority. Amongst the reasons reported for a negative attitude towards TA are conflicts within the group or (sic) trainees. It would be certainly interesting and necessary to carry out an additional study on frustrated TA trainees and to find out other reasons for a subjectively experienced failure or loss of contact (e.g. at the end of contact.". (p. 84). 


\section{Completion Rates}

One of the researcher's curiosities concerned how many trainees began training and how many actually went on to take the CTA examination. A ratio sometimes heard quoted at trainers meetings (origin unknown) was that for every 12 trainees who start training only 1 will take the final exam. One of the researcher's aims was to find out whether there was any truth to this statistic and how the statistics for TA trainees compared with other trainings. All training establishments offering TA psychotherapy training were asked to provide some statistical information regarding how many trainees they had, went for exam etc. Unfortunately only one training establishment was able to give the information requested. The participants in the research were asked for their experiences regarding the ratio of people who undertake the training and those who go on to take the CTA examination. The statistics obtained varied significantly. The most common ratio, quoted by five participants who answered the question, was 1:12 go to exam (8\%); other statistics quoted were $100 \%, 91 \%, 64 \%, 50 \%, 30 \%, 12 \% \times 2$, $11 \%, 3.8 \%$. The remaining participants declined to answer the question.

These figures may be compared with statistics of colleagues training in related fields. All the training organisations who were members of the United Kingdom Council for Psychotherapy (UKCP) were asked for their statistical information - only Body psychotherapy trainings were able to give this information; other organisations reported that either they did not keep this information or were not willing to share it. The researcher spoke to colleagues from other psychotherapy modalities of Gestalt, Person Centred, Core Process and Integrative. The general response was that the statistics for TA psychotherapy training were comparable with their experience.

Over a five year period Body Psychotherapy training centres enrolled a total of 321 students, 103 completed the training, 47 were still in training and 171 did not complete. If the remaining 47 complete their training, $47 \%$ of students who started the programme would complete their Diploma and gain professional registration.

Art Psychotherapy - over a five year period a total of 29 students enrolled on the programme. Of those, 3 students left prior to graduation, 3 were still completing (due to extenuating circumstances) and 23 graduated. For their current programme, 15 students enrolled and all are still active on the programme. This would suggest, therefore, a completion rate of $79.3 \%$. It was also pointed out that there was a significant competition for places, so for every student who was successful in their application another 4 people were refused a place. It was also noted that full time students had a higher completion rate that their colleagues who attended part-time.

Psychology - as with Art psychotherapy, it was mentioned that there was significant competition for places, the figures quoted by one University based psychology course suggest a $92 \%$ completion rate.

With regard to postgraduate levels of study in general the Higher Education Funding Council for England (HEFCE, 2013) state: "Around 73 per cent of the 11,625 students who started research degrees in English HEls in 2010-11 are projected to qualify within seven years, and around 80 per cent will qualify over a longer period." (online $4^{\text {th }}$ para)

Therefore, according to these statistics, completion rates for TA psychotherapy training in the UK appear in some cases to be well below the national average for postgraduate studies. However, looking at higher education in general the statistics for undergraduate studies suggest that the completion rates may be lower than postgraduate with figures ranging from $50 \%$ (Barefoot, 2004) to 83\% (Christie, Munro \& Fisher, 2007).

With regard to psychotherapy or psychology training, the statistics suggest that the larger or more established training programmes are more likely to put more candidates forward for final qualification and professional registration. The training establishments that have links with universities also tend to have a higher student retention rate. It may also be that students who are offered places on courses leading to a nationally recognised qualification, e.g. MA, or $\mathrm{MSc}$, where there is significant competition for places, may be more motivated to complete.

\section{Objectives}

The research questions were:

A. Why are there so many trainees in the UK leaving training before qualification?

B. Is it a problem that trainees leave without qualifying?

C. Could it be there is a discrepancy between the expectations of trainees and their actual training experiences?

D. What are the historical and cultural factors that are being passed down through the generations of TA trainers that impact on trainees today?

E. What is it that helps and encourages students to complete to exam?

F. What are the stories that trainers and trainees can tell about the exam process? 


\section{Ethical Considerations}

The ethical procedures of Metanoia and Middlesex University were followed, involving submission to a panel of a Learning Agreement. Acceptance by the panel meant that they were satisfied that the proposal paid attention to and demonstrated ethical governance of carrying out the research. No further ethics application process was needed because the participants were all self selecting.

All participants were informed of the nature and purpose of the project, the method of the data collection and the amount of time involved for the participant. All participants were asked to sign a consent form that confirmed their willingness to voluntarily take part in the project, and advised them of the right to withdraw from the project at any time without any penalty, and that no reason need ever be offered.

When interviews were transcribed, any information concerning names of people or locations, less those for Eric Berne, was removed from the transcript. Participants were under no obligation to identify any person or training establishment. A couple of participants expressed a desire to keep the identity of their trainer and training establishment confidential from the researcher in order to feel able to express their opinions without any fear or favour.

To maintain appropriate boundaries and avoid the possibility of harm, current psychotherapy trainees were excluded from the project.

At the end of each recorded interview, time was taken to debrief the interviewee, as necessary, and the participants were also given the contact details of the researcher should they have any later concerns or questions.

This project was devised as a result of the researcher's concerns about the practice of TA psychotherapy training. A balance needed to be made between accounting for the researcher's own experiences, including being open about any prejudice she may have, and the experiences of the participants in the project. With regard to the area of subjectivity bringing forth ethical concerns, it could be argued that if subjectivity is accepted, then the whole project is biased, and, consequently, of little worth, but if subjectivity is eliminated, then the research could equally become meaningless as it is the phenomenological experience that is being explored and this will, of its own accord, be subjective. The balance, here, will be between the researcher owning her own subjectivity, and with how this impacts on her view of the participants and their accounts, whilst also acknowledging that the interviews will also be subjective from the viewpoint of the participants.

Moreover, the researcher sought supervision from both her Academic Adviser (AA) and Academic Consultant (AC) and each also acted as an independent third party to ascertain if they would reach the same, or similar, conclusions as the researcher.

\section{Methodology}

Interpretive Phenomenological Analysis (IPA) was chosen because it is concerned with understanding the lived experience, and with how participants, themselves, make sense of their experiences. This can be viewed directly with the TA concept of script (Berne, 1972) whereby each person's Life Script is unique and will makes sense to the individual, but may not necessarily make sense to someone else as they have a different Script and view life through an alternative frame of reference (Schiff et al, 1975). The reader is reminded that the quotes from the participants reflect their own subjective experiences or opinions.

IPA (Smith 1995) was applied to data from 21 out of the 50 participants who had shared their training experiences during semi-structured interviews. Semi-structured interviews, based on the questions shown in Appendix A, were used to make sure the participants were asked identical questions so that comparisons and links could be made; they also gave flexibility for specific experiences to be discussed in detail. Only 21 interviews were selected to keep the project manageable in the light of the significant amount of data that was obtained. These interviews were randomly selected although care was taken to make sure each group was fully represented.

The interviews were transcribed and the transcripts read repeatedly to ensure that a general sense of the whole nature of the participants' accounts of their experiences was obtained. Notes were made of potential themes and patterns, with the process informed by the researcher's experience of the interview itself. The researcher also looked at the narratives of how the stories were told and at the cultural contexts of the training, and looked for any classification or typology. Returning to the beginning, the text - and sub-text - was re-read, and any emergent themes were identified and provisionally organised.

Once each transcript had been analysed individually, the researcher compared the themes and patterns with the other transcripts. Attention was then focused on the themes themselves to define them in more 
detail and establish their inter-relationships. The shared themes were then organised to make consistent and meaningful statements that provided an account of the meaning and essence of the experiences of the participants. The analysis of the data was initially done manually but because of the large number of interviews this became unmanageable and NVivo Computer Assisted Qualitative Data Analysis Software (QSR International 2014) was used to further refine the themes, sub-themes and collate quotes for the finished thesis. Only those themes supported by at least six participants were taken into account.

Once this had been completed, the researcher sought for explanations using transactional analysis to make a further analysis of the data received, allowing the TA concepts to emerge from the analysis already undertaken, rather than search for the concepts from the outset.

Smith's (1995) checklist was applied to validate the project:

Internal Coherence: The project analysis was reviewed at several stages by an independent researcher to ensure themes were grounded in the data. Clear, consistent and coherent links were shown between data extracts, themes and theoretical analysis;

Presentation of Evidence: There was sufficient raw data in the analysis chapter and appendices of the reseracher's original thesis to provide the independent researcher with an opportunity to test the interpretations that had been made by the author;

Independent Audit: The data - presented as draft consent forms, interview schedules, and interview transcripts - were offered to provide a clear chain of evidence from initiation enquiry to final report.

External Supervision: Throughout the project, external supervision was provided by the Academic Advisor, Academic Consultant and peers in a peerwriting group.

\section{Subjects}

Six participant groups/generations were identified, with 3 subjects in each of Groups 1-5 and 6 subjects in Group 6.

Group 1: These participants undertook some of their training with Eric Berne;

Group 2: Trainers in the USA who have been training for $5+$ years;

Group 3: 'Old' Trainers - those who have been training in the UK for 10+ years;

Group 4: 'New' trainers - those training in the UK for less than 5 years;
Group 5: UK Transactional Analysts who passed the CTA $(P)$ examination within the last 5 years;

Group 6: Trainees who left their training prior to taking the CTA exam.

The participants were self-selected; those in Groups 1 and 2 responded to personal contact from the researcher via a general email to US colleagues who fitted the selection criteria; participants for Groups 36 responded either to advertisements in professional journals or in direct response to hearing about the project from the researcher or a colleague.

By interviewing people from group 1, the researcher hoped to identify whether the core principles and philosophies that Berne wrote about were integral to his teaching and practice, to discover how the theories were developed and taught, and whether there are aspects of training TA that have been lost over time.

The interviews with people from group 2 were to gain an insight into the development and then decline of TA in the USA. The interviews with people in groups 3,4 and 5 were to provide insight into how TA has been taught in the UK over a substantial period of time. It became possible to make links and comparisons with the information gained from groups 1 and 2, thereby giving a wide and time specific view of the development of TA training in the UK.

\section{Results}

Figure 1 shows the themes and sub-themes that emerged and are described below with examples of participant comments.

\section{Gains and Losses}

\section{Gains}

\section{Life Changing}

For all of the participants in this project, it was their own personal development that was the most significant achievement that they gained from undertaking the training. Across all generations, this is a theme that was consistent.

A participant who undertook the early marathons "...never experienced being able to change so much over a month. I mean, the experience was really a life changing experience..." (Interview 5:2)

Another said "...understanding myself, really...a livelihood that I find I enjoy... what I've gained the most is how I understand me, and I think that...that's probably where I started from." (Interview 10:19)

Looking back on what they had accomplished during the training experience, for some, focused more on the academic side of the work, and having met all the requirements and completed the coursework, there is a real sense of pride and achievement. 


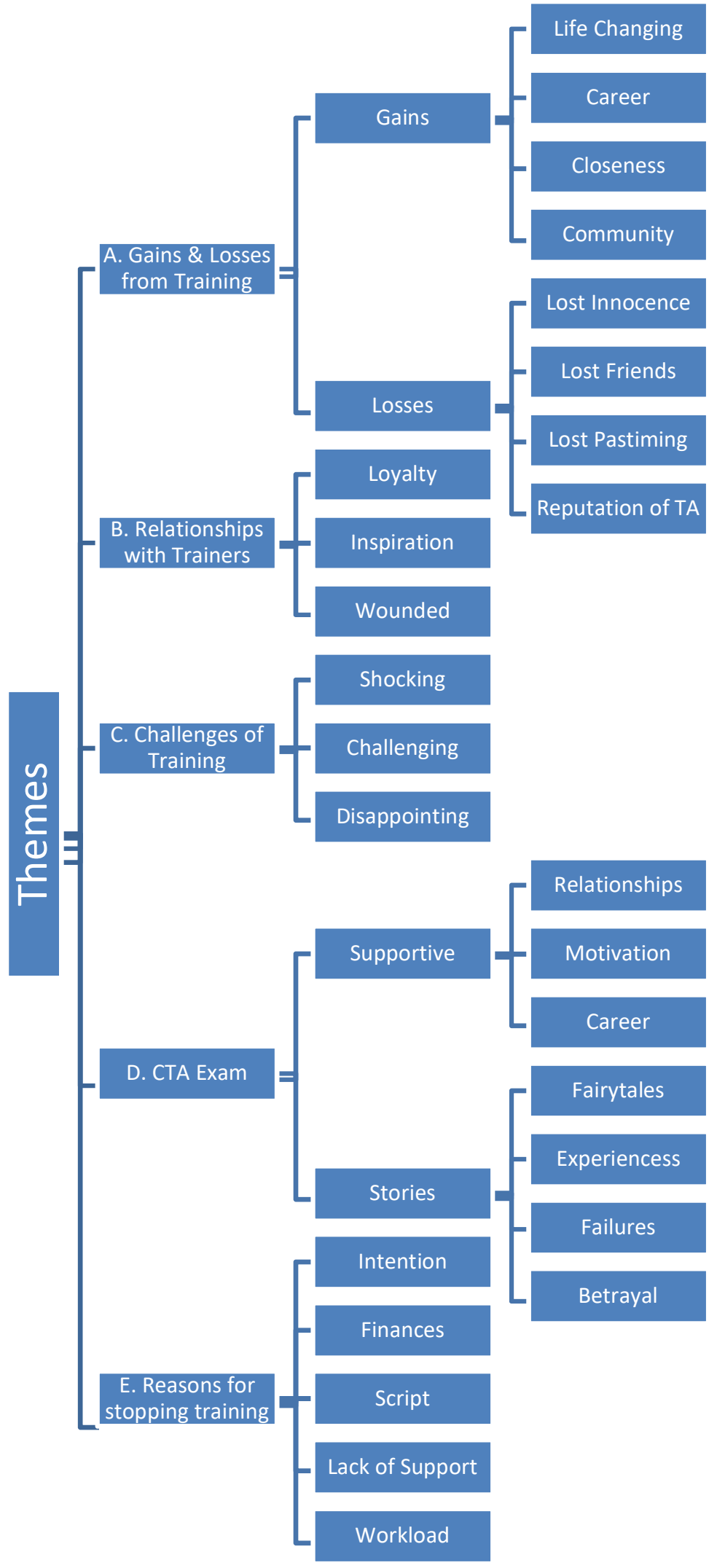

Figure 1: Themes and Sub-Themes 
“...getting clients, and, you know, and looking back from the end of the four years to the beginning, and thinking, - Wow, you know, I did that. I did all of those hoops and psychiatric placements and all of that. I did it. Yeah, a real sense of achievement..." (Interview 13:3)

"...the triumphs were...was doing the presentation at the end of each year. That was a real triumph for me." (Interview 16:5)

Even those who did not take the CTA examination have taken something from the training for themselves and applied it to other areas in their life -

"For me, it's made me very grounded, and very in touch with myself, and I look after myself and my family, well, because of all that training, so, work and home life have been much better for it." (Interview $17: 10)$

\section{Career}

This second theme covers the appreciation of the participant's ability to use TA in their working life. There is a sense of gratitude for what the training and subsequent experience has given them.

“...my whole career has been a delight, and it's forty years of a really gratifying career." (Interview 4:10)

The simplicity, stability, flexibility and depth of TA remain a basis from which the participants can integrate other theoretical approaches for both professional and self-reflection.

"It's given me a basic framework for learning about and integrating many different psychotherapy approaches." (Interview 5:5)

"An incredible set of conceptual and therapeutic tools...I keep coming back to the TA as fundamentally useful for my own reflection and conception of how I work, and also incredibly simple effective ways of helping people, and empowering people, to understand their own process, and do their own work." (Interview 9:14)

The ability to use the theory as a therapist has helped in developing a sense of identity, effectiveness and potency that is appreciated by the participants, and has been noticed by clients and others.

"...giving me a space to really find my identity as a therapist." (Interview 10:16)

“...being a potent practitioner and getting feedback from clients and observers about that." (Interview 17:10)

The diversity that TA offers in terms of the wide range of available models means that different people, using different aspects, can come up with the same conclusions. This is a source of curiosity and fascination.

"We never can understand how it is that we can all work in the same room, at the same time, and come up with the same ideas, and look at everything completely differently. So I think that that intrigues me, you know, I don't...l've never found another theoretical approach that has done that, and l've done lots of different therapeutic training." (Interview 7:10.)

\section{Closeness}

This third theme relates to the relationships that the participants have developed with their peers. The foundations of the relationships started during the training process, whether it was during a residential course, or through being a member of an active learning environment, and the longevity of the relationships was also commented upon.

“...a week's residential away together as a group... That was always just stunning. A real mixture of therapy, of thinking, of walking, talking, eating, drinking, laughing. All that sort of stuff. It was a real wonderful mixture. It was something, I think, which we all looked forward to immensely." (Interview 8:2)

"The highpoints were the friends l've met, I sense, and still have." (Interview 16:5)

“...there's a community, an international community. I love the fact that we continually develop theory, that there's intellectual stimulation, there's an emotional relationship, that it's an extraordinarily good set of theories for every aspect of life." (Interview 19:16)

Losses

\section{Lost innocence}

It seems that for nine of the participants the loss of naivety was something they identified as having been a result of the training. For them, the opportunity for denial is felt to be no longer an option, and this can be seen in the sense of others no longer being willing to accept that the participant does not know something, or in the inability to discount the reality of the situation.

"There was a time when...when I didn't understand something, it was accepted. It isn't now. I act as if, or I look as if, I cannot be deceived, which, of course, is not true, unfortunately. So I think l've lost that innocence a bit." (Interview 7:10)

"...the comfort of denial...there was something about, you know, in my old life, with the, sort of, potentially destructive patterns of behaviour that I had, there was something quite comfortable in not knowing about any of that..." (Interview 10:19) 
Through the process of personal development, whether it is via therapy, the challenging of peers and trainers, or the gaining of theoretical knowledge, the ability to continue discounting (Schiff et al, 1975), to keep our Frame of reference and, indeed, Life Script (Berne, 1972; Stewart and Joines, 1987) intact, is drastically reduced. The benefit of this is that it is less likely that the participant would get into harmful relationships or indulge in damaging or unsafe behaviours.

\section{Lost Friends}

This links closely with the previous theme, although it could be that the person concerned is no longer willing to compromise themselves as they had in the past, including with long standing relationships and even, in one case, a marriage.

"I definitely lost some friends. By choice but you know along the way I have decided to change the friendships and relationships." (Interview 19:16)

"The more I became me the less he liked me and the less I liked the way he responded to me. So. But it has, look ...yeah, I suppose, that's cost. Potentially, I wouldn't have ended my first marriage, but, actually, the benefits of that one have been huge." (Interview 11:14)

\section{Lost Pastiming}

Six participants commented that due to the high level of intimacy possible within a training group, they had less need to spend time pastiming (Berne, 1964), and in some cases were needing to re-learn this skill. Psychological game playing (Berne, 1964), was also reduced.

"I've certainly lost naivety when it comes to interpersonal communication with friends...l'm having to work hard at regaining a lightness in my personal life, which, I think, psychotherapy training educates you out of, potentially, into having much higher expectations...I have to re-educate myself into relaxed pastiming, which, I think, l've rather fallen out of through the training." (Interview 12:6)

\section{Reputation of TA}

There were comments to the effect that the theory of TA could be perceived as punishing or blaming, and also that there are negative attitudes towards TA, contributed to by the focus on simple language and the impact of misleading textbooks.

"-The only disrespect l've got for the model is that I think we have to be very careful - and I say 'we' because I use it - I think we have to be very careful when we're talking to people about 'Rackets', and we're talking to people about 'Discounting', and 'Rescuing' (Karpman, 1976), you know. I think it's quite harsh, and if somebody's really in the grip of something, and it's suggested to them, 'It's a 'Racket', you know, it may be true, but it could also send the defences even higher." (Interview 18:20)

"I probably lost all sorts of things, the little bits I know about, by being associated with TA. So, there are some very negative attitudes out in the world about $T A$, and I know there are times when people say, -Oh, her. She's TA." (Interview 19:16)

"...a negative press because it was too simple and because...that's the pit-fall of it..." (Interview 1:12)

\section{B. Relationship with Trainer(s)}

Loyalty

There were a range of comments from all the participants in Group One about how the Tuesday night seminars were a hotbed of ideas, discussion and debates, and that although Berne was the leader as the initiator of TA, he was also willing to be challenged. Issues of power and control began to emerge, the growing momentum attracted people who may not have been there for the right reasons, and a training standards committee and other systems were put into place. There was a theme of wishing to remain loyal to Berne and to the principles and the original theory of TA.

"He was very open to suggestions, feedback, confrontation and everything else, and, so, we did, and we did a huge amount of that . . . ..." (Interview 1:18)

"...the Training Standards was quite important because we had a lot of people who were opportunists coming along and becoming TA linked, or getting in on it, rather, going off and giving huge, high-paying seminars, and things like this - which bugged us a little because we were much more conservative from a financial standpoint." (Interview 1:15)

"...we were loyal to the principles. We had sibling rivalry, we'd fight ... with each other, but it was kind of in the room. Yeah, we didn't do it in public so much." (Interview 1:19)

"...use it exactly the way Eric wrote it, instead of somebody interpreting it..." (Interview 2:19)

Inspiration

The positive relationship and sense of inspiration with the main trainer continues into later generations and other trainers. 
"... (He) was an extremely bright and loving man...feel like I was his special student, that he had a really special place in his heart for me, and that he thought I was special. (Interview 4:3)

"I had experienced both [trainers] and really felt they were solid, and safe, and grounded..." (Interview 11:3)

"...something about qualities of people I respect. That, even if it all goes horribly wrong, they will be active, and come back, and do something about it." (Ibid:6)

"I got that high level of respect, and sense, that the trainers were mindful of meeting the needs of the group, and the individuals, rather than their own grandiosity of, 'Look what a great trainer I am,' type of thing." (Interview 12:3)

For some participants, their view of the trainer(s) seems to have been fairly grounded from the beginning; the level of respect was high, and there is a sense that all parties were operating from an 'I'm OK, You're OK' Life Position (Berne, 1976). For others, there is an acknowledgment that their relationship changed over time. For some, this went from idealised to being more real. The relationship seems to have encouraged some trainees to stay within the same training environment and not seek professional development elsewhere. The process of growing up is mentioned by six participants, particularly when their original training relationship had been more Parent-Child or they had perceived this in some of their peers. Some suggest that trainees even appear to return into a childlike state when with their trainer, and yet others had experienced a positive or negative impact due to a previous therapeutic relationship with their trainer.

"...like many trainees, I had quite an idealised view of my trainers to start with...And over time, I think, it becomes a little more real..." (Interview 10:4)

"...what I experienced of them as people, therapists, was that they genuinely were who they were, and that, therefore, it would be good to be one of their trainees because they would be real..." (Interview 11:23)

"My trainer's part of that system, you know...my trainer, then, was one of my first supervisors, but I did get other supervision, and, so, what happens is, I end up belonging to the training establishment, but I don't belong to the TA community. Now... and I think that was a problem where I trained, personally...there wasn't a lot of encouragement to . . . Get out there and grow up, and leave home." (Interview 10:6)

\section{Wounded}

This theme focuses further on the issue of power that continues, with thirteen participants reporting issues that appeared to them to range from unreasonable to verging on abuse on the part of the trainer towards the trainee. It would seem that for five of the participants in Group 6, this issue has been significant in both their experience of their training and also in the decision not to continue to the CTA examination. Some participants who wished to transfer to other trainers also reported negative experiences.

“...he said, 'I don't think you'll make it with her'. I said, 'Well, I'm quite interested in exploring it, and my mind had been made up, really.' I felt that they were clinging to me. Not for me, but for them, in a way, and I had been looking at this symbiosis stuff. It's the first time I had heard about it, and I was exploring it, and thinking that, - You want to do some thinking for me, here, and I can think for myself. I had obviously grown in my journey, my personal journey though TA, and it felt a bit like a stranglehold." (Interview 17:4-5)

"...she became very angry with me because I went off and did bits of training with other people...And she, sort of, needed me because I was out there in the world, a lot, and she wanted to get out in the world. So, she was very keen, and wanted to come and do training, and TA 101s in my workplace, which she did come and do." (Interview 19:8)

\section{Challenges of Training}

\section{Shocking}

This theme considers some of the personal challenges that the participants experienced during their training. For a number, it was the challenge to change how they might participate in the training group.

"The biggest personal challenge - but it also made me want to keep being there - was that I was so shy, and so depressed, and so insecure, that I wouldn't get up and participate in the training ...so it was difficult for me to be there in that I was nervous and didn't want to be called on, or put on the spot about having to do something publicly." (Interview4:5)

For some, a significant personal challenge was due to the experience of having their frame of reference consistently confronted. For one, the confrontation was direct challenge by the trainer:

"...[The Trainer said] 'Well... I'm going to make a contract with you. Your questions are really, really 
good, and they all have an angry edge to them. Since you've never met me, it's unlikely that you're angry with me but you're clearly angry about something, or angry at somebody, so, if you're willing to do something about what you're angry about, then I'll continue answering your questions. If you are not willing to do that, I'm not going to answer any more of your questions.' Nobody'd ever said that to me before... such clarity, and all. And so that's....after the 101 , I felt I'm going to learn how to do this." (Interview 6:2)

Another participant was similarly confronted by another supervisor, just prior to taking his CTA exam. At the time, the impact of this was very significant in that the participant:

"...lay down on the living room sofa and went into a catatonic state, and my wife - I told her what had happened - and she just brought me cups of tea and it was about, sort of, five hours before I could stand up after I opened the email...[On later reflection] ...he caught me out, and he was right...to confront the trainee, probably in the last few months before exam, to really go that extra bit...and that's going to be very helpful, and it will probably mean that the process in the room will go much smoother." (Interview 12:12)

Some describe the challenge as meeting a developmental deficit; they needed to take responsibility for their personal and professional requirements, describing this as a growing up process:

"I think that one of the less spoken of processes behind the developmental aspect of training and moving to CTA, and so on, is about growing up and becoming an Adult, and taking oneself seriously, as a colleague amongst peers..." (Interview 12:5)

"...that, for me, has been a big challenge and that 'accepting' who I am...” (Interview 15:7)

Consideration is given to the reality that much of the financial cost of the training pays for the personal journey, and there is also a comment that the subsequent income for some therapists does not reflect the significant financial input that the therapist has made with regard to their training:

"...the reality for a lot of people, now, is, - No. It could cost you $£ 50,000$ to do your training, and are you, actually, ever going to earn that much from it in a way that you notice? Because, certainly, lots of my colleagues, who are CTAs, if they're in private practice, they're, maybe, earning $£ 10,000$ a year, and when you think you've got, like, a master's level qualification, that's rubbish. And I think there's a slight amount of collusion around, still, about saying, -'Yes, yes, there will be clients', and, -'Yes, this is the hourly rate', and, -Blah blah, and, that thing about, - 'A lot of this is your personal journey.' That's what you might be paying for, actually." (Interview 11:26)

\section{Challenging}

As mentioned in the previous theme, nine participants generally regarded the group as 'challenging but positive'. This theme considers the group dynamics and group process with regard to the impact of the group dynamic on the participant.

For some, their perception was that the group experience was balanced, for others it was rather more disruptive and challenging, and for some there was a sense of inconsistency that included a sense of unfairness and irritation that others were not doing the same as them.

"The group was on the one hand very challenging and very supportive, which was a nice combination..." (Interview 9:7)

"Challenges were to do with other people in the group; the group dynamic; group process. We had a group that went through a lot of change and had various, sort of, episodes within that, so there were outsiders who came into the group, there were people who, within the group, were very disruptive...had a situation where two people in the group had an affair...all sorts of nice, exciting processes that must have been really difficult for the trainer to hold, really. Thinking now... and l'd be thinking, - 'Oh, O.K.' And, at the time, those felt like...it fell into my stuff about...-'l like all.. these people, - I want everybody to like each other,' and it really fed into my stuff of, - 'This is not O.K.' And, yet, it was O.K., and it happened, but I found it very, very difficult to be a part of." (Interview 11:7-8)

"...[What] I didn't like was that there were people along the way in first, second year, who weren't in therapy, and who weren't in that training to be psychotherapists..." (Interview 12:2)

"... [I] didn't like the fact that, at times, I would, maybe, be doing a lot of the sharing of vulnerability and stuff because I was in therapy, and others were very 'Be Strong' because they weren't in therapy." (Ibid:3)

"...the tutor was very challenging to one of the people in the group, and that was important to me because I thought it needed to be done, and it felt containing to me, but, also, that TA didn't need to be a nurturing soft option, you know, when the boundaries need to be put in place, and people needed to be challenged, that it could happen." (Interview 13:3) 
“...they weren't real, and that, therefore, it didn't feel safe to be in that group, and that a number of other places where l'd had little tastes of this, or tastes of that, was all about, 'Let's all say the right words and smile the right smiles, but you don't really have to look at what's in you that you don't like, or that might be difficult, or uncomfortable, or unpleasant, even'." (Interview 11:23)

\section{Disappointing}

One of the characteristics of many TA training programmes is to run a multi-level training group, with one of the advantages of this being the breadth and depth of knowledge within the group. Whether trainers are offering multi-level courses or not, a good trainer will be able to pitch the training at a level, or levels, that will meet the needs of, and utilise, the expertise of the all the trainees. Unfortunately a couple of the participants considered that they did not have this experience.

“...left me feeling a little bit disillusioned because a lot of the material I was being taught I knew, because l'd already studied it in my degree, and a lot of it I knew at a better level than I was being taught...I'm not really being fed at the level I want to be fed..." (Interview 10:4, 11)

"I found it hard that I didn't know much about TA at all and also I'm not totally sorted myself and whenever I tried to say that I didn't know I was sort of told that of course I had a great deal of knowledge and they kept saying that I was discounting myself and it got, it really got up my nose and there was something about modesty. I'm coming from a place I'm not discounting myself but being fairly modest and realising my limitations and there was a lot about TA that they was, because I went into the second year. ... So there's a lot I didn't know. So there was all of this that I didn't feel that I could actually say that I didn't know and when I did I was told I was discounting." (Interview 18:6)

Nine participants experienced a sense of disillusionment when they realised that what they were required to do on the course or for CTA exam was not what they had expected they needed to do, or that they had lacked understanding of the training requirements.

“...so I had a breach of trust, really...'You haven't told me everything that there was to know about this side of it', and myself and the group would query it. ... This is just like 'pyramid sales' ...I had bought into it. Why I hadn't asked questions was because of where I was in my journey, and I put them on a pedestal, I suppose, and I hadn't done the sort of grounded checking that I would do if I was joining a course now. So, I think it was a Script thing going on from them, and from me, and other members of the group, as well..." (Interview 17:4)

"I was angry that I, perhaps, hadn't, kind of, fully known what it all involved." (Interview 20:6)

\section{The CTA Exam}

\section{Supportive}

\section{Relationships}

This theme focuses on the significance of specific relationships that the participants found supportive during the examination preparation stages, and, for some, the relationship was with a specific person, whereas for others it was the sense of group identity that they found supportive.

"I was there with somebody who was doing it." (Interview 10:25)

"I needed someone completely away from all this process, for me and my Script, in order... to get through that last bit." (Interview 15:14)

“...it was never really a question that you wouldn't do it in our group, it was something about the collective energy that was there and that sense of group identity but it also had sense of, you know, the group influence, and the group demand, that you just go and do your CTA. So, for me, that was the experience, there was no other choice that I wasn't going to do it." (Interview 8:9)

"It really was about a sense of belonging..." (Ibid:8)

"I was always in a peer group of people preparing for exam...l think that was really important, having a peer group. Had a peer group right from the very start, and we're still in the same peer group eleven years later. Three of us." (Interview 15:12)

\section{Motivation}

This theme concerns the personal determination of the participants themselves. For many, the question was not really about whether they would take the exam, but, rather, when they would do it, and the personal motivation that sustained them during the process.

"...there was no lack of motivation. I was going to do my exam, sometime, and that was it." (Interview 15:12)

“...it's a bloody long process, and you've really got to know that you want to do it." (Interview 10:23)

"...it was a re-decision for me. I will finish this process..." (Interview 12:10)

\section{Career}

Some saw the CTA exam as a way of proving they were competent psychotherapists. In the early days 
of TA in the USA, before state regulation, the CTA exam was recognised as being of value.

“...the TA certification was a way to get a legitimate credential that let the public know that I was competent to call myself a transactional analyst, and, at that point, that had some recognition because there weren't yet all the licensing categories and everything that we have now." (Interview 5:8)

"I really wanted a career, and this was the career I wanted, so, I think, there were lots of factors. I had time. Money wasn't an issue. I really had inclination, and was enjoying it, and wanted the sense, wanted the whole sense of achievement and fulfilment, and I really wanted the end product of the career, so it was 'masses' keeping me going." (Interview 13:8)

"...there was still that real sense of motivation, momentum, you know. It wasn't a case of the four years training and an exam, it was, actually, 'This is five years training'." (Interview 11:19)

It is interesting to note that all of the themes in this part have directly linked to the themes under 'Gains', in the earlier part of this section. The personal motivation and desire for a new career or development of their existing career, coupled with group cohesion, appears, for many, to run simultaneously.

Stories

Fairytales

This theme focuses on the CTA exam stories that participants have heard during their training process, or subsequently. Their nature is explored in order to understand why there appears to be excessive trepidation about the exam process. Understandably, some people may feel some anxiety around exams.

For the earliest generations of TA in the USA, the stories were merely descriptive but for later generations there were various stories circulating that suggested hidden processes.

“....at that point, people were allowed to sign up for the board that they wanted. There were sheets put up with the board member's names and you could...Look, the ostensible purpose for that was to make sure you weren't on an examining board with anyone who had supervised you previously, or trained you, or whatever, so that they could be objective about your work. The secondary...the 'secret' motivation was to make sure you got a board that people knew was made up of good people who would be positive examiners. And, so, the word, kind of, got out about who was 'Good', and who was 'Not so good'." (Interview 5:9) "...a fantastic body of history into which people tap for all their hopes, fears, fantasies, desires, excitements, hatreds, etc, etc, you know, so we've got this bloody enormous fairytale of ideas, and what have you, into which people can do whatever they choose to do. I don't think that that was there for us." (Interview 8:9)

"...mainly that some people had to resubmit and it was a, sort of, a huge, big thing, and very traumatic, and, also, that the actual exam was quite traumatic for some people. That some people were quite...l think, felt quite unfairly treated...the impression I get is that it's not necessarily a positive experience. It can be quite bad, and it can be good, and then, when you get it, it's just, kind of, just this huge thing that now you've got it..." (Interview 21:20)

"...stories that came out were indirect, and were through the modelling of people in years above me. I was the first slice of people from the training to go to CTA, and I went in year seven of my training, and...with two colleagues...three colleagues. One from year eight, two from year nine and one from year ten...yeah...So I think that there was a message, by modelling, that it takes a long time to get to CTA." (Interview 12:10)

\section{Experiences}

This theme considers positive experiences of passing the CTA examination. There is a sense, in a number of these, of utter relief at passing, and also some acknowledgment of their own process in terms of preparation for the exam.

"I was known as being this bright young person, so, I think, they asked me questions but they expected me to have coherent, straightforward, accurate answers. So, they asked those questions, and I did, and then they asked me to turn on my tape and I turned on my tape to a point where I was asking someone to go back in time to find an early decision scene, and [name] was on board, they were all hungry, he said, 'O.K. I've heard enough! She passes!'...It was a little anti-climactic, but I was relieved, and I was happy, and I got all those strokes that you get when you pass an exam." (Interview 4:20-21)

"I got a perfect score and, so, I was really excited about that - that was a great experience." (Interview 5:3)

“...when I didn't know something, or I went into a 'Don't think' injunction, I would label it, and I found it absolutely delightful. I thought this is brilliant, not like any other way of being examined like you're really being examined, a lot, on how you manage the process under stress..." (Interview 12:11) 
"...in a sense, it was a very good experience but, actually, I was aware of finding it difficult..." (Interview 13:18)

\section{Failures}

Stories in the UK about exam failures seem to have appeared between the third and fourth generation. The participants in Groups 1-3 do not report hearing much about either the CTA exam, then called the 'Clinical Member' exam, or the TSTA, then called the 'Teaching Member' exam.

"Some people didn't pass back then, but it's usually because they really didn't know some significant stuff." (Interview 4:18)

"...(the) board felt more like trying to trap me, or something, and it was much more of a negative experience, and it was kind of challenging, intimidating...not helpful in terms of really allowing me to demonstrate my knowledge." (Interview 5:3)

"It wasn't very good. It was, actually, a pretty miserable process...it was a nasty experience. It was very competitive... and I passed. Was not pleasant." (Interview 6:12)

"...accused in one of the exams of being too nice..." (Interview 4:20)

Betrayal

There is a sense of anti-climax, or disappointment mixed with relief at having passed - such as disappointment that only one of the three prepared tapes were used in some oral exams. Most of the comments under this theme were about the oral exam but there were also significant comments about written exams.

"...my board had only just met, and they were arguing amongst themselves, and the chair didn't sit. Oh, it just felt like a complete nightmare...l just, somehow, got lost in the middle of it all." (Interview 15:16)

“...when I did get the feedback, my supervisor was, she was really shocked and was incensed and then stories came out that lots and lots of people got deferred and...there wasn't an appeal...procedure so it just felt, I felt betrayed by the system...I think it might have been easier had I understood at the beginning that this was a fairly...common experience that people got deferred and that they didn't like their feedback and they didn't like the reason of being deferred....and then some of the feedback just didn't make sense so...I was holding this stuff that wasn't making sense and what do you do with that? So yeah I felt completely let down by the sort of the whole TA system. Yeah it was a really shocking experience and I felt as if I hit up against a brick wall. I was really angry about it." (Interview 13:9)

“... most likening to a lottery - in some ways. ... there was stories about who was a bad marker and who was a good marker, who wanted this, or who wanted that, and, at the end of the day, it seemed to be, -'Well, you've just got to send it in,' and that's where...the bit about the lottery, it seemed, at the end." (Interview 15:13)

Reasons for Stopping Training.

\section{Intention}

This theme considers the participants' views on the reasons why trainers may take trainees into their training programmes, and why trainees may go into training for reasons other than taking the CTA Psychotherapy exam.

"I suppose it depends on who you're recruiting, in part. You know, if you're trying to fill a training programme and you're taking in quite a lot of people, fairly widely, then you can expect only a few to carry through, I suppose, and, maybe, the training is more demanding in terms of the case study and the written work, now, than it used to be." (Interview 9:17)

"...some trainers have taken people onto their training courses who don't have any intention of qualifying the CTAs - that are actually doing it purely for personal development." (Interview 10:23)

"They (the trainee) get(s) seduced into psychotherapy training and then, of course, can never get the hours, and, actually, probably don't ultimately want to." (Interview 19:19)

"I think...people enter the training for the wrong reasons. So, originally, TA training was an additional training for people who were already counselling psychotherapists. Now it's a training from the start, and you have two sorts of people going in ... How the hell do people know they want to be a therapist if they've never had it? ...I think you'll find lots of people enter TA training the first year, the foundation year, for personal development." (Interview 19:19)

"So, they're using it as therapy more than learning." (Interview 10:23)

For some, there is a realisation that what they thought they would have, as a result of doing the training, is not going to happen.

"I think...I certainly didn't have enough information, in the beginning, to know what was, sort of, coming, later on, and, also, how other institutes handle things, so I was really only informed about my institute, and, also, I think, not in very great detail." (Interview 21:15) 
"So, I can see why it's not really made explicit, but I also think there's a lot of people who get half way through and realise, and feel let down, and angry, and betrayed, and exploited, even...(They say) -l'm paying all this money and not going to get anything back, actually." (Interview 11:27)

“...a bit more of a realistic idea of how people work because that's something that I'm only, sort of, gradually finding out. I think, initially, when people say, -'Well, okay. You're charging something like thirty pounds an hour for clients, and you can see up to twenty clients a week,' and people go, -'Mmmmm. Thirty pounds an hour times twenty? This is how much income I can have,' and the reality [with my peers is that], one after the other, stopped working as a therapist because they can't make it work financially. I think it's that that's something that I think, in some shape or form, has to change because it seems that not only me but a lot of people go into it thinking, - 'Oh, yeah. That would be great to, kind of, -have an income through that,' and then find out that they can't..." (Interview 21:15-16)

\section{Finances}

Finance clearly plays a significant part in a trainee's expectations of training, their lifestyle and future plans. For the participants who did not go to exam, one of the reasons for not continuing was because of the cost of doing the training with added expenses, such as personal therapy. This was sometimes accompanied by a perceived loss in lifestyle options, due to reduced income, and the uncertainty whether it would be worth taking the financial risk.

"I've always thought about, maybe, going part-time, and seeing clients one day, and stuff like that, but l'm thinking, - 'Would I still have the same money?' and all of that stuff..." (Interview 16:15)

"I think it's really difficult for people, and it's very expensive, as well, ...if you take your therapy seriously..." (Interview 18:25)

"I'm asking myself the question about the further future because, from the therapists that I know a lot of them, kind of, do it in the evening, after their day job, and l've not really come across anyone who's been able to finance a living with seeing private clients if they haven't got a job with a monthly income, somewhere..." (Interview 21:12)

\section{Script}

In this theme, 'personal process' is significant. This appears to be the opposite of the theme about Gains as life changing. It is the realisation that change would be required, personal or professional.

“...There're always workshops going on, kind of. 'How to be good at getting your CTA', and, I thought,
-I don't particularly like that, either. You know, leave your script behind, and all this...I think there is something about...it's, like, if you don't want to go and do the CTA, or you fail the CTA, or in preparation of CTA, you've, kind of, got to park your vulnerable side. You've got to park your, kind of, your script. You've got to, kind of, put that out the way, and I think, _-'Oh, yeah?'... and it's somehow...it seems to me to, sort of, pathologise the trainee...I have got a script, and, so, my script would be present in the CTA. I can't leave my script behind. I can, and have, done lots of, kind of, work on all that, whether in TA or out of TA. I don't need TA to do that, but I just didn't like what I saw, and what I learnt that people had to do." (Interview 20:4)

"...realised the influence if they chose to go there, the influence upon their work life, their relational life, their children, their...you know, and, so, what they do was they, kind of, stopped, and they thought, 'Do I actually want to meet that challenge?'...they realise they didn't want to take that next step, or they weren't ready for it..." (Interview 8:7)

"...found it too close to home...gets too scary on a personal level..." (Interview 21:19)

The nature of the trainee's script also impacts upon their relationship with the trainer and/or the group and/or their therapist.

"...the transferential relationship breaks down and the trainees aren't necessarily willing to go through the negative transference with their trainers." (Interview 10:23)

"I think attachment issues are quite big in making an attachment to a trainer because they are lovely or because they represent a parent or whatever and its more for the journey than the end qualification." (Interview 17:15)

"It's largely to do with having unsatisfactory work with their therapists, or therapists that don't challenge them sufficiently. They enter a symbiosis with them when it's good money for four years. But there's no Script change there." (Interview 12:8)

"...something rather peculiar going on in the training, which is both seductive, but also undermining, and I think that's another reason why people don't go on, and then, I think, you've got the sort of things that I was describing - not unique to [my training], you know, quite pathological stuff going on in the training, involving the trainer and trainee." (Interview 19:20)

\section{Lack of support}

Five participants have referred, in earlier themes, to feeling well supported during the training and exam preparation process. This theme now considers the participants who felt they experienced the opposite. 
“...the sadness that I hadn't found someone that would parent me, not in a confused way, but in a clear... as a leader way, 'This is the way to go, and I will support you in your development, and I'll challenge you', and, you know, I think that's what I'm looking for, but I probably wasn't in a place where I could let myself have that before..." (Interview 17:9)

"...when I was training there - that they did the years of training and it's, like, they came out of the training course at the other end and it's, like, what? And there wasn't a, sort of, structure in place...there wasn't anything to support people [in] transition from ending training to...through to moving towards their, you know, their CTA...It didn't feel like that was a supported process." (Interview 10:7)

“...there's no structure to that. There's not much support as far as I can see." (Interview 21:19)

The sense here is that the training became rather insular and exclusive, tending to only look inward at the training programme and not outward towards professional qualification and occupying a place within the wider TA community. In addition, there is also a sense of the trainee's perception that they are left to 'get on with it' should they wish to continue towards the examination. Conversely, another participant suggests that the training can become rather too containing:

“...there's the rolling structure, or a four year modular structure, etc, that, I think, for people, is easy to manage because it has a coherence of its own, and, I think, in some ways, it can protect you from asking the more vulnerable questions which are about you as an individual, and in what direction you want to take your life." (Interview 8:11)

\section{Workload}

This theme recognises the amount of work required to both continue with the training and to undertake the CTA exam process, and there is an interesting addition to examine at this point. Four of the participants in Groups 1 and 2, who are mainly in the USA, experienced the training and examination process as too much work or noted that licensing is required to be able to apply TA, so the TA training becomes an 'add-on'. In the UK, however, many trainees start from the beginning. Some of the participants in this project were already working in the helping professions, e.g. social workers, probation officers, teachers, etc. A few had done some counselling training beforehand, and there are also a significant number for whom this was a complete change of career. As a consequence, the training requirements for the participants would have been diverse, depending upon what training they had already completed.
"You should not go into TA with nothing. Why should TA be teaching you from zero? TA should be teaching you TA is a tool. As an 'add-on'. And it was never intended...even Berne was fighting the psychoanalysts. He's the one who told [another] to go and get a PhD in psychology....and who told everybody... go and get your 'psychiatry!'...and Berne would not have...thought me qualified...if I hadn't had my own credentials. So Berne didn't want psychoanalysts, as such, but he wanted credentialed people." (Interview 3: 23)

“...it's a bloody long process, and you've really got to know that you want to do it." (Interview 10:23)

"I think training to be a psychotherapist is hard. It's not just the book learning, is it? It's...you know, it's all the other things, like they have to do the psychiatric placement, they have to get their hours, and a lot of people have got a job, you know, where they are doing something totally different..." (Interview 18:25)

"...some people taking up five, six, seven, eight years between the end of this four years training to their CTA exam, and all that seems a hell of a long way." (Interview 21:12)

This suggests that the people who do take and pass the exam have completed a very substantial training programme, and, perhaps, should be justly proud of what they have achieved. The evidence that some do feel this way can be seen in the earlier theme under 'Gains and Losses'.

\section{Discussion}

In addition to analysing the data into the themes described above, it can be considered more directly in terms of the original research questions. This also led to the realisation that there were some additional questions that could usefully have been explored.

Why embark on TA psychotherapy training? It became apparent that trainees embark on the training for a variety of reasons. These influence the results for the $1^{\text {st }}$ study question about why trainees leave the training. In the earlier generations in the USA and the UK - Groups 1 to 3 - the participants were already working with clients in various capacities, e.g. as psychiatrists, social workers, counsellors etc. All but one had additional professional qualifications prior to starting their training, and one was undertaking another professional qualification, concurrent with their TA training. All had heard about TA in connection with their current working environment. From Group 4 onwards, the initial contact with TA for many of the participants was during personal therapy. Some had already embarked on a variety of counselling/ psychotherapy training programmes, but it seems to 
have been their personal therapy that prompted them to start training in TA. For the participants in Group 6 , four out of the six first heard about TA from their therapists. The other two heard about TA from employment-based training. Hence, participants in Groups $1-2$ went into training to enhance their current professional work. For Groups 3 - 5 the motivation was for a change of career, and, with Group 6, two of the participants were mainly motivated to gain personal insight and development, and the other four participants were looking to work in a psychotherapeutic capacity as a consequence of their experience in personal therapy.

\section{Trainer Motivations}

Two further questions manifested themselves only as the project analysis evolved:

\section{Why do trainers start a training course?}

2. How do trainers assess trainees before they take them into their training programme?

In the theme 'Relationship with Trainers', there are comments concerning the psychological processes that were evident to the trainees. In particular, mention is made of narcissistic processes, and the transferences that would have emerged as a result would undoubtedly influence the training experience for all involved. The personal therapy of trainees and, therefore, of trainers is also a significant element of the training experience. Although often seen by many humanistic psychotherapy training establishments as important, but separate, to the main training, in the psychoanalytic field personal analysis is the first stage of training. In other modalities, personal therapy is not viewed as explicitly necessary, but only that there is evidence of some personal development.

In the UK, personal therapy requirements were made explicit by the UK Council for Psychotherapy relatively recently (UKCP, 2003). It is, therefore, quite possible that, for a number of participants in this project, the personal therapy requirements, both for the trainee and their trainer, would have been far less specific. This, in turn, may suggest that some trainers/trainees may not have had sufficient therapy, and that, consequently, some of their unresolved issues may well be acted out in the training environment. Transferences will happen in training, but it is how they are managed that is important, and this process will begin when the trainer decides to start a training programme.
A. Why are there so many trainees in the UK leaving training before qualification?

B. Is it a problem that trainees leave without qualifying?

To deal first with $B$, it may not be a problem if trainees leave before qualifying because they were attending for personal development, although they may have an impact on other students. The main problem is when they leave prematurely when they have begun their training with the intention of qualifying. The reasons for leaving in such cases may be multifaceted, and may of course involve unconscious script issues. The reasons given by the Group 6 participants for leaving the training focus on either practical or psychological reasons.

\section{Practical reasons}

Practical reasons included costs of the training but also for therapy, supervision, books, etc plus a reduction in income as they would have needed to reduce their working hours, and time constraints due to working full-time whilst running a private practice, or attending placements, supervision, therapy sessions and the training course.

Nine participants stated that they were unaware of the requirements and were shocked when they found out; some were unsure whether they were informed at the beginning and others were adamant they had not been. This led to feeling misled and feelings of resentment and disillusionment. Some identified a perceived lack of support in preparing for the CTA exam, and of being left to their own devices once they finished their initial four-year training programme.

Both of these issues raise ethical questions. One of the core values in the EATA ethical code is selfdetermination and the principles that follow on from this are respect, empowerment and protection. In order for trainees to make a clear, informed choice about the nature and method of the training they need to be given more than just basic information.

Academic abilities were also mentioned by eight participants as being particularly challenging. The amount of written work undertaken by trainees varied, but one issue that frequently gave rise to comments was the CTA examination process. There is clear evidence that some found the experience challenging and rewarding, but for others it was not such a positive experience and one possible reason 
for this is the developing nature, process and purpose of the examination. Participants commented that they felt they were not sufficiently intelligent to reach the required standard; or there was difficulty in gathering sufficient experience without any interim qualification; or that lack of placement opportunities made clinical experience difficult to attain.

\section{Psychological Reasons}

Five of the participants in Group 6 had specific concerns about the professionalism and integrity of at least one of their trainers during their training. Such experience undoubtedly impacts on whether the trainee continues in their training, or whether, subsequently, they will take the exam. Of these five participants, two left their original training and joined a different training group. Interestingly, both of these participants chose to move away from psychotherapy training and began training in another field of TA, this highlights an additional issue of whether the trainees are made aware of or informed about the other fields of TA which may, in fact, be more appropriate.

Some participants in the project experienced issues with a trainer during their training, and these tended to focus on issues of power. Some suggest there were dependency issues being re-enacted, some refer to incongruence between what the trainer was verbally advocating and how they then actually behaved, and, although some were able to put this aside, others felt confused or even abused by what they had experienced. Transferential issues are clearly seen throughout this project. If this were a psychoanalytic training programme, then the focus of the training may deal explicitly with this phenomenon, but because it is not there is a possibility these issues may not get addressed. Furthermore, many training establishments are sole trainers so the issues, unless externally supervised, may not even see the light of day. One participant felt that her grievances had not been resolved satisfactorily, and others suggest that some trainees may be dissatisfied but do not voice their concerns to the trainer

Furthermore, personal issues of the trainees appear to have been stimulated by experiences on the training programme. Naturally, undertaking psychotherapy training will involve an exploration of the trainee's personal history, but whilst most participants experienced their training as actually reparative in this respect, there were some who felt that their experiences on the training had either exacerbated their personal issues, or they felt that the trainer was acting out their own personal issues to the detriment of the trainee.
C. Could it be there is a discrepancy between the expectations of trainees and their actual training experiences?

For most participants, expectations and experiences were comparable. Without exception, all of the participants in this project experienced personal change as a result of undertaking their psychotherapy training. For most of them, this part was seen as beneficial, but for others it was seen as needing to adapt, and this has been an unexpected and, sometimes, unwelcome experience for the participant. The most significant consequence of the training that had not been accounted for prior to training was the amount of personal change that the participants would undertake. The majority of the participants were generally appreciative of these changes, despite losing some relationships as a result, but some participants suggested that these personal changes could be one of the reasons for trainees leaving training where the trainee was not willing, or, at that time, able, to deal with the challenges to their existing relationships that would have been necessary had they continued in training. At the heart of a humanistic psychotherapy and TA in particular is the notion of 'personal growth, development and change', and the notion of change is evident throughout this project.

D. What are the historical and cultural factors

that are being passed down through the generations of TA trainers that impact on trainees today?

\section{Language}

The language of TA was intentionally devised to be easily understandable, and this is something that initially appealed to many of the participants, and continues to be appreciated. A few participants in Group 1 consider that some of the more recent developments have not held this basic principle in mind, but, for the most part, the practical and pragmatic nature of the theory continues to be taught today. One participant in Group 1 suggested that the language Berne used has not always translated well into other languages, and this may have led to misunderstandings relating to basic concepts and ideas. For example, the term 'racket' has a specific meaning in TA, but the translation of the word 'racket' could probably refer to something akin to 'tennis racket' if the translator was not clear on the original meaning of the word in the TA context.

\section{Method of training}

The early generations of TA were trained in small groups, with some participants attending marathons that would last anything between a few days to a fortnight and others were taught using recordings of 
TA 101 courses, or in group training courses/ discussions. There are a few training centres in the UK offering marathons but they are in addition to a main training programme, rather than being the main route to training. The more formal, structured approach to training appears to have become the norm, certainly in the UK, with the majority of training courses being run over weekends, usually for ten weekends per year.

One of the main differences between the first two generations and the most recent generations concerns the amount of training the trainees have completed prior to starting their TA training. The founders of TA had their first qualifications either in psychiatry, social work or counselling, and TA was then an add-on to this. This is still the case in the USA and in many European countries. The requirement or expectation of similar first qualifications in the UK is not always sought, and some of the participants in the project have queried whether this is supportive or unsupportive of TA and TA trainees.

\section{Examination}

One participant explained that the CTA exam was established, primarily, to restrict the numbers of people who could use TA. "...there were two goals. 'One', to keep the psychoanalysts out. And 'Two', establish that $T A$ is just as good as psychoanalysis..." (Interview 3:8) One consequence of this 'limiting' is a sense of an 'us and them' attitude. In The CTA Exam theme, examples are offered of both positive and negative experiences. What is clear is that the examiner, both of the written and the oral exams, potentially holds a significant amount of power, making them the 'gatekeepers' of the TA community.

E. What is it that helps and encourages students who complete to exam?

The main motivating factor was the personal motivation of the participant, and the encouraging and supportive relationships with the trainer/principal supervisor and peers.

The majority of participants who undertook the CTA examination were motivated to qualify as a psychotherapist from the beginning of their training, whereas for the participants in Group 6, their intention for undertaking the training was less directed towards qualification as a CTA.

Furthermore, the modelling of the TA Philosophy in particular, by the trainer or principal supervisor, supported the learning experience for the participant, and the congruence between their words and actions validated their trustworthiness for the participant.
Moreover, the willingness of the trainer to be challenged, and for trainees to question and disagree, was also effective in supporting the participant to take ownership of their own training and professional development.

Additionally, the participants who gained the most from their training, and, hence, their learning experience, appear to have undertaken it with a training establishment having a humanistic approach to teaching and learning, that would also appear to be in keeping with TA philosophy.

F. What are the stories that trainers and trainees can tell about the exam process?

The stories are explored in detail under the theme of The CTA Exam. Many of the 'stories' that the participants' had heard about the CTA exam were incongruent with the majority of their actual experiences, and tended to focus on negative behaviours of exam markers or board members. Whilst a few participants did report some element of negative experience, it was either their own personal process that caused a difficulty, or some aspect of competitiveness on the part of the exam marker or board member. The majority of participants experienced their written exam as a challenging process, mainly due to the amount of work necessary.

The 'stories' tend to suggest that the CTA exam is something to be feared, and some of this appears to be due to the lack of clarity regarding the exam process; a few participants reported that they felt that the exam had, at one time during their training, been 'shrouded in mystery', and this led to a sense that the CTA exam was an 'exercise in terror', rather than a standard conclusion to the training. Perhaps, with additional support and/or information, some may have been able to make a different decision based on reality rather than fantasy.

Achieving success in the CTA examination means that the trainee now 'belongs' in the TA community, so the exam could be viewed as a rite of passage. Consequently, to 'fail', or to be 'deferred', suggests a lack of belonging, or worse, rejection by the TA community, as the exam candidate is perceived to be 'not good enough'. This fear of rejection may be sufficient for the 'stories' to be given more weight than the actual events, which may then mean again that the trainee may not consider all their options.

\section{Limitations}

There are a number of limitations to this research. Firstly this study mainly refers to psychotherapy trainees in the UK and USA; it would be interesting to see what would emerge from trainees in all fields and in other countries. 
Secondly this paper refers to 21 participants' phenomenological experiences and these accounts are therefore subjective and consist of each participant's opinions and views. Similarly the researcher's own subjectivity will have played a part in how the data was analysed, although care was taken to validate the data and the findings.

Thirdly, further research into trainees' experiences of the training itself as they go through the training process would be valuable; similarly exploring the trainer's experience of the same training group would also be of interest. This is currently an ongoing project with trainees from three different training centres in the UK.

Finally the researcher used IPA as a method for analysing the data, IPA is not normally used for projects involving more than 10 people, and therefore it would have probably been easier to use another type of thematic analysis which may have generated additional themes. Similarly the research was data heavy with over 480 pages of transcript and on reflection the outcomes may have been discovered using focus groups which would have been less onerous.

\section{Conclusion}

The research has yielded much information in response to the initial questions and has led to the identification of the five themes and some subthemes as shown in Figure 1. From that, it is possible to suggest a number of recommendations for further action.

It appears that there is a definite need for trainees to be provided with more information, which could be given in writing and also might be provided in briefings and perhaps by having current or former students at such briefings, and which should include:

- financial implications, not just of the training but also for personal therapy, supervision, books, etc, and the impact on their current earnings due to the potential need to reduce their working hours

- time implications, such as the need to reduce working hours, with an explanation about the need to run a private practice, attend placement, have supervision and therapy sessions as well as the training course and additional personal study time, and all accompanied by the need to balance this with work and family commitments

- resourcing implications, alerting trainees that they will need to find a placement, arrange their own therapy, organise their supervision and TA principal supervisor, and set up in practice if they are not already a psychotherapist
- training requirements in enough detail that trainees can make a clear, informed choice about the nature and method of the training, including its academic requirements, and so that they are aware of factors such as the CTA examination, professional registration, and that there are various possible routes to qualification/registration

- an emphasis on potential students understanding that psychotherapy training is likely to lead to significant personal changes, and that this may interfere with existing relationships, accompanied by encouragement from the training establishment for trainees to consider in depth their motivation for embarking on psychotherapy training

- an emphasis on what trainees can do if they have concerns during their training, whether this be about practicalities or about dynamics within the training group or between student(s) and trainer(s)

In addition to providing more information to potential students, training establishments/individual trainers might also wish to consider their own processes including:

- their own motivation for running a training programme and how this impacts on the nature of the training provided

- how they locate the teaching and learning methodology within a humanistic and transactional analysis framework

- how they evaluate the personal motivation of potential trainees as part of their initial assessment process

- how they ensure that potential trainees have been given sufficient information to enable the trainees to make an informed choice

- the benefits of having an exit interview/debrief at the end of each year, or when a trainee leaves the programme

Dr Cathy McQuaid is a Teaching \& Supervising Transactional Analyst (Psychotherapy) and can be contacted on cathymcquaid@cornwalltherapypartnership.co.uk

\section{References}

Atkinson, P., (2006). Personal therapy in the training of therapists European Journal of Psychotherapy and

Counselling, 8(4), 407. 
Barefoot, B.O. (2004) Higher education's revolving door: confronting the problem of student drop out in US colleges and universities. Open Learning: The Journal of Open, Distance and e-Learning Volume 19, Issue 1. London. Carfax Publishing.

Barrelet, L. \& Merlo, M. (2006) Training in systemic therapy. [French]. Psychotherapies, 26(4), 233-239.

Bartoli, E. (2007) Religious and Spiritual Issues in Psychotherapy Practice: Training the Trainer. Psychotherapy: Theory, Research, Practice, Training, 44(1), 54-65.

Bennett-Levy, J. (2006). Therapist skills: A cognitive model of their acquisition and refinement. Behavioural and Cognitive Therapy, 34, 57-78.

Bergin, A.E., Payne, R.I. and Richards, P.S., (1996) Values in psychotherapy. In: E.P. Shafranske, ed, Religion and the clinical practice of psychology. Washington: American Psychological Association, 297-325.

Berne, E. (1964) Games People Play. New York. Grove Press.

Berne, E. (1968) A Layman's Guide to Psychiatry and Psychoanalysis. Third Edition. New York: Simon and Schuster.

Berne, E. (1972). What do you say after you say hello? New York. Grove Press

Berne, E. (1976). Classification of positions. Transactional Analysis Bulletin Selected Articles from Volumes 1-9. San Francisco: TA Press. (Original work published 1962).

Bjerre, P., (1964) The teaching of psychotherapy. Praxis der Psychotherapie, 9(5), 193-201.

Blohm, F.,(2006) The Analytic Triad - Indirect countertransferences in the psychotherapeutic process and training. Forum der Psychoanalyse: Zeitschrift fur klinische Theorie \& Praxis, 22(4), 358-373.

Bondolfi, G. \& Bizzini, L. (2006) Training in cognitivebehavior therapy. [French]. Psychotherapies, 26(4), 211220.

Bonds-White, F. (2003) Anatomy of a Training Group. Transactional Analysis Journal, 33(4), 344-349.

BoswellL, J.F. and Castonguay, L.G. (2007) Psychotherapy Training: Suggestions for Core and Future Research. Psychotherapy: Theory, Research, Practice, Training, 44(4), 378-383.

Boud, D. \& Walker, D. (1998) Promoting Reflection in Professional Courses: the challenge of context. Studies in Higher Education, 23, 2, 191:206

Carkhuff, R.R. and Truax, C.B., (1965) Training in counseling and psychotherapy: An evaluation of an integrated didactic and experiential approach. Journal of Consulting \& Clinical Psychology, 29(4), 333-336.
Carlsson, J. and Schubert, J., (2009). Professional values and their development among trainees in psychoanalytic psychotherapy European Journal of Psychotherapy \& Counselling, 11(3), 267 - 286.

Castonguay, L.G. (2005) Training Issues in Psychotherapy Integration: A Commentary. Journal of Psychotherapy Integration, 15(4), 384-391.

Chance, E. (1965). Training in analytic group psychotherapy: Observations on some learning problems in the dimension of power. International journal of group psychotherapy, 15(3), 291-302.

Christie, H. Munro, M. and Fisher, T. (2004) Leaving university early: exploring the differences between continuing and non-continuing students. Studies in Higher Education. Volume 29, Issue 5. London. Carfax Publishing.

Clarke J. I. (1996). The synergistic use of five TA concepts for educators. Transactional Analysis Journal, 26, 214219.

Coffield, F. and Moseley, D. and Hall, E. and Ecclestone, K. (2004) Should we be using learning styles? What research has to say to practice. London: Learning and Skills Research Centre.

Colledge, R. (2002) Mastering Counselling Theory (Palgrave Master). Basingstoke. Palgrave Macmillan.

Consoli, A.J. and Jester, C.M. (2005a) A Model for Teaching Psychotherapy Theory Through an Integrative Structure. Journal of Psychotherapy Integration, 15(4), 358-373.

Consoli, A.J. and Jester, C.M. (2005b) Training in Psychotherapy Integration II: Further Efforts. Journal of Psychotherapy Integration, 15(4), 355-357.

Corey, G. (2008) Student Manual for Theory and Practice of Counselling and Psychotherapy 8th Revised edition. Belmont. Wadsworth Publishing Co Inc.

Cornell, W.F. and Hine, J. (1999) Cognitive and social functions of emotions: A model for transactional analysis counselor training. Transactional Analysis Journal, 29(3), 175-185.

Cornell,W.F. (1994) Dual Relationships in Transactional Analysis: Training, Supervision, and Therapy Transactional Analysis Journal, Volume 24 No 1

Dellis, N. P., and Stone, H. K. (1960). The training of psychotherapists: A multidisciplinary approach. In The training of psychotherapists: A multidisciplinary approach, Feb, 1959, Southeast Louisiana Hospital, Mandeville, LA, US; The chapters of this volume, and their respective discussion sections were derived from presentations at the aforementioned symposium. . Louisiana State University Press. 
Derner, Gordon F., and Russell R. Monroe. An interpersonal approach to training in psychotherapy. In The training of psychotherapists: A multidisciplinary approach, Feb, 1959, Southeast Louisiana Hospital, Mandeville, LA, US; The chapters of this volume, and their respective discussion sections were derived from presentations at the aforementioned symposium. Louisiana State University Press, 1960.

Elliott, R. and Zucconi, A. (2006) Doing research on the effectiveness of psychotherapy and psychotherapy training: A person-centered/experiential perspective. Person-Centered and Experiential Psychotherapies, 5(2), 81-100.

Elliott, R., Watson, J.C., Goldman, R.N. and Greenberg, L.S., (2004) Recommendations for teaching and learning process-experiential therapy. USA: American Psychological Association.

Evans, G. (2007) Counselling Skills for Dummies Hoboken, New Jersey, John Wiley \& Sons.

Fauth, J., Gates, S., Vinca, M.A., Boles, S. and Hayes, J.A. (2007) Big Ideas For Psychotherapy Training. Psychotherapy: Theory, Research, Practice, Training, 44(4), 384-391.

Feltham, C. (2006) Review of Power, Interest and Psychology: Elements of a Social Materialist Understanding of Distress and The Future of Training in Psychotherapy and Counselling: Instrumental, Relational and Transpersonal Perspectives. British Journal of Guidance \& Counselling, 34(1), 133-137.

Feltham, C.P.D. (2005) Evidence-Based Psychotherapy and Counselling in the UK: Critique and Alternatives. Journal of Contemporary Psychotherapy, 35(1), 131-143.

Fertuck, E.A. (2007) Review of Evidence-based Psychotherapy: Where Theory and Practice Meet. Psychotherapy: Theory, Research, Practice, Training, 44(1), 115-116.

Freeston, M., Cromarty, P., and Thwaites, R. (2006). Training therapists: Self-reflection in learning about the nature of anxiety and its implications. Paper presented at European Association for the Advancement of Behavioral and Cognitive Therapy, Paris.

Friedlander, S. R., Dye, N. W., Costello, R. M., \& Kobos, J. C. (1984) A developmental model for teaching and learning in psychotherapy supervision. Psychotherapy, 21, 189-196.

Geldard, D. and Geldard, K. (2005). Practical Counselling Skills Training: An Integrative Approach. Basingstoke. Palgrave Macmillan.

Geldard, K. and Geldard, D. (2002) Counselling Skills in Everyday Life. Basingstoke. Palgrave Macmillan.
Ginger, S., (2009) Legal status and training of psychotherapists in Europe European Journal of Psychotherapy \& Counselling, 11(2), 173 - 182.

Gordon, A.B. (2007). Review of Education and training in solution-focused brief therapy. Journal of Marital \& Family Therapy, 33(2), 285.

Greben, D.H. (2004) Integrative Dimensions of Psychotherapy Training. The Canadian Journal of Psychiatry / La Revue canadienne de psychiatrie, 49(4), 238-248.

Halgin, R.P., (1985) Teaching integration of psychotherapy models to beginning therapists. Psychotherapy: Theory, Research, Practice, Training, 22(3), 555-563.

HEFCE (2013) Postgraduate research degree qualification rates improving.

http://www.hefce.ac.uk/news/newsarchive/2013/news8278 5.html Accessed 12 December 2014.

Hearst, L.E., (1990) Transference, countertransference and projective processes in training course block sessions. Group Analysis, 23(4), 341-346.

Hillier, Y. (2005) Reflective Teaching in Further and Adult Education. 2Rev Edn. London. Continuum International Publishing Group Ltd.

Horton, I. (2002) Universities are not a good place for psychotherapy and counselling training: A response to lan Parker. European Journal of Psychotherapy, Counselling and Health, 5(4), 379-385.

Hough, M. (2006) Counselling Skills and Theory 2 edn. London. Hodder Arnold.

Hovaguimian, T. and Markowitz, J. (2006) Training in interpersonal psychotherapy. [French]. Psychotherapies, 26(4), 221-232.

Jacobs, M., (2000) Psychotherapy in the United Kingdom: past, present and future. British Journal of Guidance \& Counselling, 28(4), 451-466.

Jacobs, M., (2002) 'That psychotherapy and counselling trainings should be based in universities' European Journal of Psychotherapy Counselling \& Health, 5(4), 347.

Jones, A. (1991). Formal training is antithetical to the spirit of psychotherapy: A review and commentary Counselling Psychology Quarterly, 4(1), 65.

Jones, S (2006) The psychotherapeutic understanding of organisational function: Shadow and transparency DPsych Thesis Metanoia Institute and Middlesex University.

Kauffman, K. and New, C. (2004) Co-Counselling: The Theory and Practice of Re-evaluation Counselling (Advancing Theory in Therapy) 1st edn. Abingdon. Brunner-Routledge. 
Klain, E., (1975) Transference situation in the educative group. Psihijatrija Danas, 7(2-3), 173-179.

Knight, C. (2005) Humanistic psychotherapy training: Significant experiences contributing to the perceived competency development of exceptional humanistic psychotherapists. In Kjell E. Rudestam and Rae R. Newton (2007) Surviving Your Dissertation: A Comprehensive Guide to Content and Process Thousand Oaks. Sage.

Ladany, N. (2007) Does Psychotherapy Training Matter? Maybe Not. Psychotherapy: Theory, Research, Practice, Training, 44(4), 392-396.

Langs, R., (1992) Boundaries \& frames: Non-transference in teaching. International Journal of Communicative Psychoanalysis \& Psychotherapy, 7(3-4), 125-130.

Leader, D., (2006) To what extent is personal therapeutic experience and external validation essential in therapeutic training? European Journal of Psychotherapy and Counselling, 8(4), 387-391.

Leszcz, M. (2004) Reflections on the Abuse of Power, Control and Status in Group Therapy and Group Therapy Training. International journal of group psychotherapy, 54(3), 389-400.

Lytle, P.F., (2007) Teaching clinical competence. Pragmatic Case Studies in Psychotherapy, 3(3), 55-64.

Maslow A (1987) Motivation and Personality (3rd edition) New York: Harper and Row.

McLemore, C.W. and Court, J.H. (1977) Religion and psychotherapy: Ethics, civil liberties, and clinical savvy: A critique. Journal of Consulting \& Clinical Psychology, 45(6), 1172-1175.

Melnick, J. and Brandsma, J.M., (1977) Teaching psychotherapy as an adventure. Psychotherapy: Theory, Research \& Practice, 14(2), 196-201.

Minton, D. (2005) Teaching Skills in Further and Adult Education. 3Rev Edn. Andover. Cengage Learning.

Nelson-Jones, D.R. (2005) Theory and Practice of Counselling and Therapy Fourth Edition. London. Sage Publications Ltd.

Nelson-Jones, R. (2004) Introduction to Counselling Skills: Text and Activities Second Edition. London. Sage Publications Ltd.

Nelson-Jones, R. (2007) Basic Counselling Skills: A Helper's Manual 2Rev Edn. London. Sage Publications Ltd.

Nelson-Jones, R. (2008) Introduction to Counselling Skills: Text and Activities Third Edition. London. Sage Publications Ltd.
Newton T. (2003) Identifying Educational Philosophy and Practice through Imagoes in Transactional Analysis Training Groups. Transactional Analysis Journal, 33(4), 321-331.

Nowak, R. (2013) The effects and effectiveness of being trained in Transactional Analysis. An empirical study International Journal of Transactional Analysis Research 4:1 81-84

Palmer, S. and Barnes, S .(2001) Values And Ethics In The Practice of Psychotherapy And Counselling Maidenhead. Open University Press.

Parker, I. (2002) Universities are not a good place for psychotherapy and counselling training. European Journal of Psychotherapy, Counselling and Health, 5(4), 331-346.

Proctor, G. (2002) The Dynamics of Power in Counselling and Psychotherapy: Ethics, Politics and Practice Ross on Wye. PCCS Books.

QSR International (2014) NVivo -

http://www.qsrinternational.com/what-is-qualitativeresearch.aspx accessed 16 December 2014

Ravitz, P. and Silver, I.,(2004) Advances in Psychotherapy Education. The Canadian Journal of Psychiatry / La Revue canadienne de psychiatrie, 49(4), 230-237.

Reece, I. and Walker, S. (2007). Teaching Training and Learning: A Practical Guide. 6 Rev Edn. Houghton-leSpring. Business Education Publishers Ltd.

Reiss, N.B. (1975) Problems in the teaching of psychotherapy. Psychotherapy: Theory, Research \& Practice, 12(3), 332-335.

Rieken, B., (2003) Counter-transference problems, analysis of relationship, and self-disclosure in the shadow of psychotherapy training. Examples arid reflections in individual psychological view. [German]. Zeitschrift fur Individualpsychologie, 28(4), 332-353.

Rizq, R. (2007). On the margins: A psychoanalytic perspective on the location of counselling, psychotherapy and counselling psychology training programmes within universities. British Journal of Guidance \& Counselling, 35(3), 283-297.

Robertson, M., (1976) Teaching Psychotherapy Through an Experience Rather Than an Explanation. Professional Psychology - Research \& Practice, 7(2), 246-248.

Robertson, M., (1984) Teaching psychotherapy in an academic setting. Psychotherapy: Theory, Research, Practice, Training, 21(2), 209-212.

Rogers, C. R. (1961). On becoming a person: A therapist's view of psychotherapy. London: Constable. 
Russell, R.L. and Staszewski, C., (1988) The Unit Problem: Some Systematic Distinctions and Critical Dilemmas For Psychotherapy Process Research. Psychotherapy: Theory, Research, Practice, Training, 25(2), 191-200.

Schiff, A.,\& Schiff,J. (1971) Passivity and the Four Discounts. "Passivity". Transactional Analysis Journal 1, vol1, pp71-8

Schiff, J.L; Schiff, A.W; Mellor, K; Schiff, E; Schiff, S; Richman, D; Fishman, J; Wolz, L; Fishman, C; Momb, D. (1975) Cathexis Reader: Transactional Analysis Treatment of Psychosis. New York. Harper and Row.

Schroder, A., (2004) Psychotherapy training in united Europe: The conditions of things. [German]. Verhaltenstherapie \& Psychosoziale Praxis, 36(3), 631638.

Shepherd, K.R.D. (2004) Some Philosophical Critiques and Appraisals: An Investigation of Perennial Philosophy, Cults, Occultism, Psychotherapy, and Postmodernism Derby. Citizen Initiative.

Smith. J.A. (1995) Semi-structured interviewing and qualitative analysis. In J.A. Smith, R. Harre and L. Van Langenhove (Eds) (1995) Rethinking Methods in Psychology, London: Sage.

Snow, L.H. and Rickels, K., (1965) Use of direct observation in the teaching and learning of psychotherapy. American Journal of Psychotherapy, 19(3), 487-491.

Spence, D.P. (1997). A Critique of Postmodern Theory in Psychotherapy. Journal of Nervous \& Mental Disease, 185(4), 279,280.

Stauble, W.J., (1965) Training group psychotherapists. The Canadian Psychiatric Association Journal / La Revue de l'Association des psychiatres du Canada, 10(3), 216222.

Stewart, W. (2005) An A-Z of Counselling Theory and Practice - 4th Edition Andover. Cengage Learning.

Stewart, I; Joines, V. (1987) TA Today. A New Introduction to Transactional Analysis. Nottingham. Lifespace.

Sue, S. and Zane, N. (1987) The Role of Culture and Cultural Techniques in Psychotherapy: A Critique and Reformulation. American Psychologist, 42(1), 37-45.

Tantam, D., Deurzen, E.V. and Osterloh, K., (2001) The Survey of European Psychotherapy Training 2: questionnaire data European Journal of Psychotherapy, Counselling \& Health, 4(3), 379 - 395.

Taylor, E.W. (2001) The Theory and Practice of Transformative Learning: a critical review. Information series no. 374. Online. Available HTTP: <http://files.eric.ed.gov/fulltext/ED423422.pdf> Accessed 31 October 2014.
Thienemann, M. and Joshi, S.V. (2007) Teaching Evidence-Based Psychotherapies. Child and adolescent psychiatric clinics of North America, 16(1), 183-206.

Thorne, F.C. (1944) A critique of nondirective methods of psychotherapy. Journal of abnormal psychology, 39(4), 459-470.

Tileston, D.E.W. (2000) Ten Best Teaching Practices: How Brain Research, Learning Styles, and Standards Define Teaching Competencies. Thousand Oaks. Corwin Press.

Tolan, J. (2003). Skills in Person-Centred Counselling \& Psychotherapy (Skills in Counselling \& Psychotherapy Series) London. Sage Publications Ltd.

Trotzer, J.P., (2006) The counselor and the group: Integrating theory, training, and practice ( 4th ed.)New York, New York: Routledge/Taylor \& Francis Group

Truax, C.B., Carkhuff, R.R. and Douds, J., (1964) Toward an integration of the didactic and experiential approaches to training in counseling and psychotherapy. Journal of Counseling Psychology, 11(3), 240-247.

UKCP (2003) Minutes HIPS Meeting May 2003. p.9, points 03/41.2.01 to 03/41.2.03. In UKCP (2011) Training Standards of Humanistic and Integrative Psychotherapy Section of UKCP. Appendix 5 http://www.ukcp.org.uk/search?search=training+standards \&id=1\&sisea offset=20 Accessed 31 October 2014.

Van Deurzen, E.V., (2001) Psychotherapy training in Europe: similarities and differences European Journal of Psychotherapy Counselling \& Health, 4(3), 357.

Van Rijn, B. Wild, C. Fowlie, H. Sills, C. van Beekum, S (2011) Impact of Transactional Analysis Psychotherapy Training on Self Awareness and Ability for Contact. International Journal of Transactional Analysis Research Vol 2 No 1, January 2011: 16-24.

Van Rijn, B; Sills, C; Hunt, J; Shivanath, S; Gildebrand, K; Fowlie, H (2008) Developing clinical effectiveness in psychotherapy training: Action research. Counselling and psychotherapy research Vol 8, No 4 Routledge

Walsh, R., Perrucci, A.; Severns, J. (1999) What's in a Good Moment: a Hermeneutic Study of Psychotherapy Values Across Levels of Psychotherapy Training. Psychotherapy Research, 1468-4381, Volume 9, Issue 3, 1999, Pages $304-326$

Watters, W.W., Rubenstein, J.S. and Bellissimo, A., (1980) Teaching psychotherapy: Learning objectives in individual psychotherapy. The Canadian Journal of Psychiatry / La Revue canadienne de psychiatrie, 25(2), 111-117. 
Watts, M.H., (2006) 'Therapeutic training after Freud': To what extent is personal therapeutic experience and external validation essential in therapeutic training? European Journal of Psychotherapy and Counselling, 8(4), 415.

Wheeler, S. and Miller, H. (2002) Counselling and psychotherapy: Should it be taught in universities? Review of three papers. European Journal of Psychotherapy, Counselling and Health, 5(4), 407-414.

Whitaker, C.A. and Miles, H.H.W., (1960) The on-going training of the psychotherapist. In Dellis, N. P. and Stone, H.K. (eds) The training of psychotherapists: $A$ multidisciplinary approach, pp.151-172 Feb, 1959,
Southeast Louisiana Hospital, Mandeville, LA, US; The chapters of this volume, and their respective discussion sections were derived from presentations at the aforementioned symposium. Louisiana State University Press.

White, K., (2004) Developing a secure-enough base: teaching psychotherapists in training the relationship between attachment theory and clinical work Attachment \& human development, 6(2), 117-130.

Zhang, L. (2009) From conceptions of effective teachers to styles of teaching: Implications for higher education. Learning \& Individual Differences, 19(1), 113-118. 


\section{Appendix A: Interview Questions}

1. How did you hear about TA/Eric Berne in the first place?

2. What were the significant factors that attracted you to TA?

3. What were your expectations when you started TA training?

4. What were the factors that influenced your training experience?

5. How did you make sense of those experiences?

6. What were the high points and the challenges?

7. What do you think of TA today when compared with when you did your initial training?

8. If you could change anything about TA what would it be?

9. What have you gained most by training in and using TA?

10. What, if anything, have you lost?

11. What do you think Eric Berne would say about TA today?

12. Who are the significant people in TA for you and why?

13. In the UK only about 1 in 12 people who start training actually go on to take the CTA exam - is this your experience?

14. Why do you think there is such a high drop out rate? / Why do you think there is there such a discrepancy between the UK and your experience?

15. What kept you motivated to continue and qualify?

16. What stories were you told about the CTA exam process?

17. What was your actual experience of it?

18. What do you say to trainees about the CTA exam?

19. What do you think could be done to increase the number of people who stay in training and continue to CTA?

20. Is there anything else you would like to say about your experiences as a trainee / trainer / supervisor that may help future generations of TA practitioners? 